\title{
TERRA BRASILIS, TERRA AUSTRALIS - PARTE 03: ANÁLISE DE ESTRATÉGIAS E POLÍTICAS PARA PLANEJAMENTO E GESTÃO DE CIDADES
}

\author{
Bruno Borges Mamede ${ }^{1}$
}

\author{
Lucas Devides Moreno²
}

\section{Cláudia Ribeiro Pfeiffer ${ }^{3}$}

\begin{abstract}
RESUMO
Este artigo faz parte de uma série de estudos sobre as proximidades estruturais e sistemáticas entre Brasil e Austrália. Em especial nesta edição, serão relatadas e analisadas as estratégias, políticas e recursos utilizados em algumas cidades de ambos os países para combater seus principais problemas urbanos. Considera-se aqui, como na totalidade da pesquisa, que ambos os países possuem mais semelhanças do que discrepâncias em diversos aspectos da administração de seus territórios nacionais e, nesta passagem, os aspectos de planejamento e gestão urbana são o pontochave de parametrização e análise.
\end{abstract}

Palavras-Chave: Geografia Urbana, Engenharia Urbana, Administração Pública.

\section{BRASILIS TERRA AUSTRALIS LAND - PART 03: ANALYSIS OF STRATEGIES AND POLICIES FOR PLANNING AND MANAGEMENT OF CITIES}

\footnotetext{
${ }^{1}$ Comunicador Social (PUC-Rio) e Geógrafo (UERJ), Aluno de Mestrado em PEU/POLI/UFRJ e de Especialização em IPPUR/UFRJ, bruno.mamede@poli.ufrj.br.

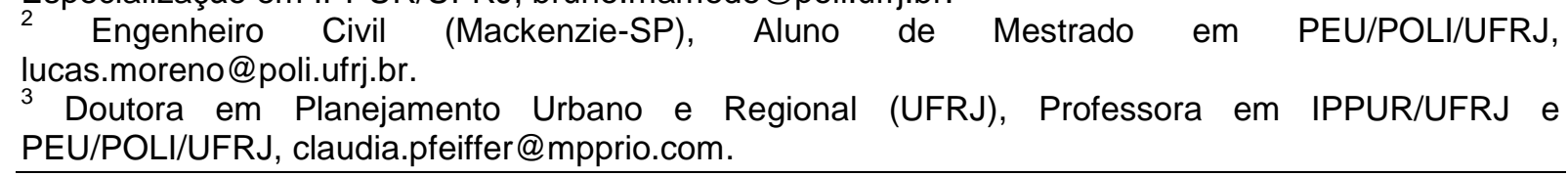




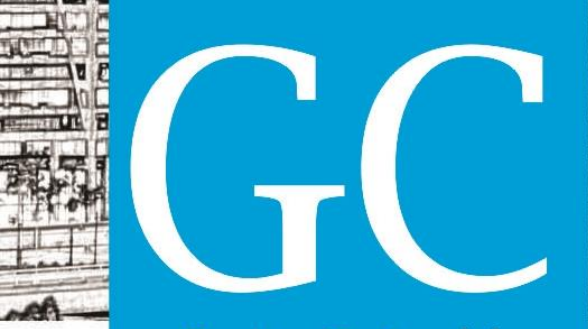

Revista Nacional de

Gerenciamento de Cidades

\section{ABSTRACT}

This article is a part of a studies' series about the structural and systematical proximities between Brazil and Australia. Particularly in this issue, there will be related and analyzed strategies, politics and resources applied in some cities of both countries to deal with their main urban problems. It is regarded in here, as in the whole research, that these two countries have more resemblances than discrepancies in many aspects of their national territories administration and, in this written, the aspects of urban planning and management are the key points of parameterization and assay.

Keywords: Urban Geography, Urban Engineering, Public Administration.

\section{BRASILIS TERRA AUSTRALIS TIERRA - PARTE 03: ANÁLISIS DE LAS ESTRATEGIAS Y POLÍTICAS PARA PLANIFICACIÓN Y GESTIÓN DE LAS CIUDADES}

\section{RESUMÉN}

Este artículo hace parte de una serie de estudios acerca de las proximidades estructurales y sistemáticas entre Brasil y Australia. Especialmente en esta edición serán analizadas estrategias, políticas y recursos aplicados en algunas ciudades de los dos países para resolver sus principales problemáticas urbanas. Se ha considerado acá, como a toda la pesquisa, que estos dos países presentan mucho más semblanzas que discrepancias en muchos aspectos de la administración de sus territorios nacionales y, en este trabajo, los aspectos de planeamiento y gerenciamiento son los puntos-llave de parametrización y análisis.

Palabras-Clave: Geografía Urbana, Inguinaria Urbana, Administración Pública.

\section{1- INTRODUÇÃO DA TERCEIRA PARTE: PROPOSTA E OBJETIVO}

Conforme mencionado, o objetivo deste artigo está em apresentar de forma comparativa as principais estratégias de planejamento e gestão de algumas cidades e estados no Brasil e na Austrália para, logo a seguir, aproveitar-se dos pontos positivos e negativos de cada situação para esboçar uma estratégia mais adequada para o gerenciamento de cidades em cada um destes países.

A justificativa para este trabalho está pautada na formulação de uma abordagem mais direta e propícia para a abordagem dos problemas urbanos de cada cidade baseada não somente no enfoque teórico, mas também na incorporação elementos empíricos nas estratégias de gestão e planejamento. 

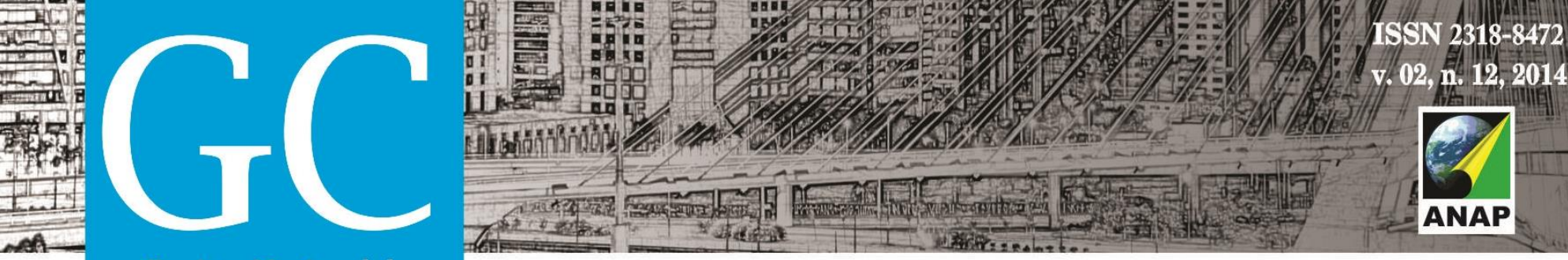

Revista Nacional de

Gerenciamento de Cidades

\section{2- GESTÃO DAS CIDADES: URBANIZAÇÃO E PLANEJAMENTO}

De forma geral, cidades em todo mundo experimentaram uma revolução ímpar ao longo dos séculos XIX e XX, com seu grande crescimento e a mudança na concentração de populações ao longo dos espaços nacionais. Na Europa Ocidental e na porção anglo-saxônica da América do Norte e também no Japão, o crescimento destas cidades é percebido desde meados do século XVIII, quando nestes países surgiram as primeiras indústrias e políticas específicas de cercamentos e expulsões de populações de áreas rurais, gerando assim oferta de mão de obra barata e pouco qualificada para trabalhar nas novas indústrias urbanas.

Entretanto, o processo de urbanização não foi uniforme em todo mundo e, em grande parte dos países ocorreu tardiamente ou ainda está em curso. No tocante aos continentes de América do Sul e Oceania, observam-se a formação de poucos países com indústrias com uma grande gama de complexidade, um número um pouco maior de nações com algumas poucos indústria com pequena ou média complexidade e, por fim, alguns outros com industrialização primária ou praticamente nula. Desta maneira, ao analisar esta informação sobre o prisma clássico de fomento da urbanização por meio da implantação de indústrias nos territórios nacionais.

De acordo com Freestone (2007) e Santos (2007), tanto no Brasil como na Austrália, a indústria incipiente surgiu em algumas cidades que já possuíam destaque no contexto nacional, a exemplo das cidades de São Paulo (SP) no Brasil e Sydney (NSW) respectivamente (atualmente as maiores, mais ricas e importantes de seus países). A consolidação e expansão da atividade industrial em níveis regional e nacional é um dos fatores responsáveis pelo crescimento de algumas metrópoles nacionais (IBGE, 2014) e grandes cidades capitais (ABS, 2014), as quais exercem grande influência e ocupam o topo das hierarquias nacionais.

De acordo com Correa (2006), o crescimento das cidades em diferentes níveis ao longo do tempo e do espaço forma uma rede urbana com algumas 

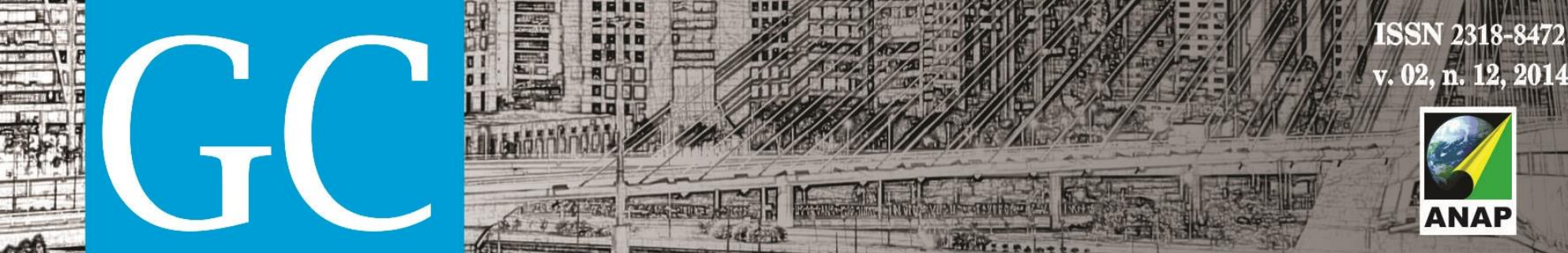

Revista Nacional de

Gerenciamento de Cidades

cidades exercendo o papel de articular todo o território em diferentes níveis (nacional, regional e local). Retomando os exemplos anteriores, São Paulo é a principal cidade brasileira, onde estão não apenas produtos e serviços de maior complexidade nacional, como também o início de toda a rede de fluxos de transportes para todo território nacional e para outros países também. Sydney exerce a mesma função ao articular territórios remotos e longínquos dentro das porções continental e insular da Austrália.

Não apenas as grandes cidades, mas também aquelas de médio porte são planejadas para atender a objetivos específicos. Mildura (VIC) na porção Noroeste do estado teve seu desenho urbano reformulado no período pós-2 ${ }^{\mathrm{a}}$ Guerra Mundial para atender os novos fluxos logísticos oriundos de armazéns, centros de processamento e beneficiamento de gêneros agrícolas municipais e regionais4. Atualmente, a cidade é um centro agrícola local com serviços destinados especificamente a este setor. A cidade brasileira de Paranavaí (PR) possui história semelhante: ao início do século $\mathrm{XX}$, com o crescimento da agricultura nas regiões Norte e Nordeste do estado5. A cidade converteu-se em um entroncamento logístico entre estados e regiões, demandando a reformulação de sua área urbana para receber novas atividades econômicas e, concomitantemente, aumentando sua participação no contexto regional.

Nos dois casos mencionados, percebe-se que o planejamento urbano foi utilizado como forma de reformular e preparar a cidade (bem como o território) para receber novas atividades provenientes de um ciclo econômico em ascensão. A partir do crescimento econômico a reformulação das áreas já existentes bem como o planejamento de áreas futuras para receber novas populações e demandas assume importância singular para a devida gestão e administração de

\footnotetext{
4 De acordo com Victoria Government (2014), a Cidade Rural de Mildura (conforme divisão administrativa estadual) é a maior produtora nacional de uvas, sendo a sua região (a qual também inclui localidades no estado vizinho de Nova Gales do Sul - NSW) por $80 \%$ desta fruta em toda Austrália. Também é conhecida nacionalmente como Cidade da Uva e do Vinho.

${ }^{5}$ De acordo com IBGE (2014), o Município de Paranavaí aproveitou-se do momento de expansão das lavouras cafeeiras a partir do Oeste do vizinho estado de São Paulo. Décadas posteriores, com a expansão da fronteira agrícola para a região Oeste Paranaense e também outras no estado de Mato Grosso do Sul, tanto este como outros municípios já importantes em contexto local tiveram sua importância reafirmada em contextos regional e estadual.
} 

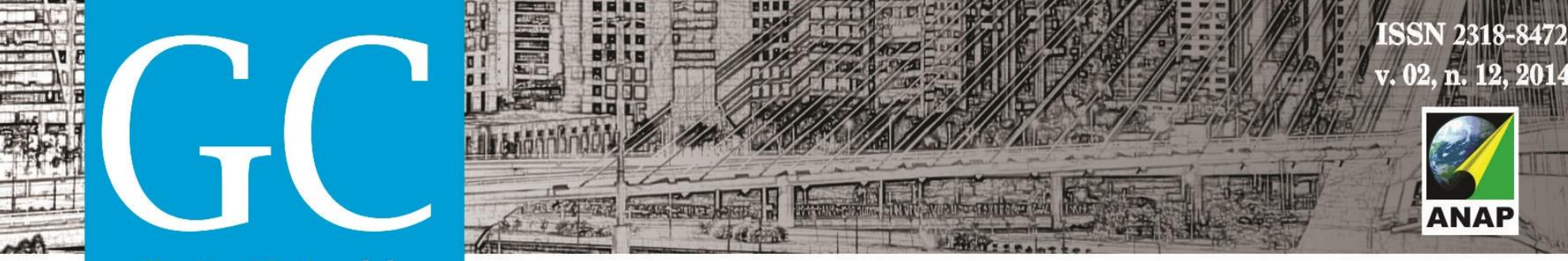

Revista Nacional de

Gerenciamento de Cidades

e apresenta, além das atividades propostas inicialmente também concentra 0 maior parque industrial da região bem como um dos principais portos do país. Da mesma maneira, a nova capital de Minas Gerais foi concebida no intuito tornar-se um centro administrativo e nódulo conector entre as diversas regiões do estado. $\mathrm{Na}$ atualidade, Belo Horizonte é a quarta maior metrópole brasileira, o maior parque industrial e centro logístico do estado, fomentado também pela proximidade equidistante às cidades de São Paulo a Sudoeste, Rio de Janeiro (RJ) ao Sul e a capital federal Brasília ao Norte.

Percebe-se em ambos os países que, apesar do planejamento urbano não ser seguido nos anos futuros de forma totalmente estrita ao plano original, muitos governantes estimulam a diversificação tanto econômico-produtiva como de uso e ocupação. A partir deste momento, adaptações ou adendos são realizados ao plano original ou, então, novos planos são realizados com base nas novas situações existentes. Desta maneira, percebe-se que para além do planejamento urbano são necessários efetivos de aferição e continuidade das medidas anteriormente praticadas, fatores estes que são incumbência da administração e gestão dos territórios.

Ainda no tocante a estruturação das áreas urbanas, Ferraz (2004), Corrêa (2007) e Santos (2007) mencionam que dentro dos sistemas componentes de uma cidade, um dos principais é o de mobilidade interna e externa, possibilitando a expansão da própria mancha urbana bem como o uso seccionado de áreas específicas (como bairros residenciais afastados dos industriais, por exemplo). Logo, os sistemas de transportes locais e regionais são os principais estruturadores das políticas urbanas e, a maneira como estão dispostos influenciam diretamente o uso e ocupação do solo além dos perfis demográficos, etários e econômicos das populações residentes em cada área.

Duas metrópoles merecem destaque devido à ampliação diversificada de suas matrizes de transporte municipais6: Melbourne (VIC) na Austrália e Rio de

\footnotetext{
${ }^{6}$ Todas as informações aqui mencionadas foram obtidas por ANTT (2014) e DIT (2014) com base nos relatórios anuais de investimentos e presença de modos de transportes em cada município.
} 

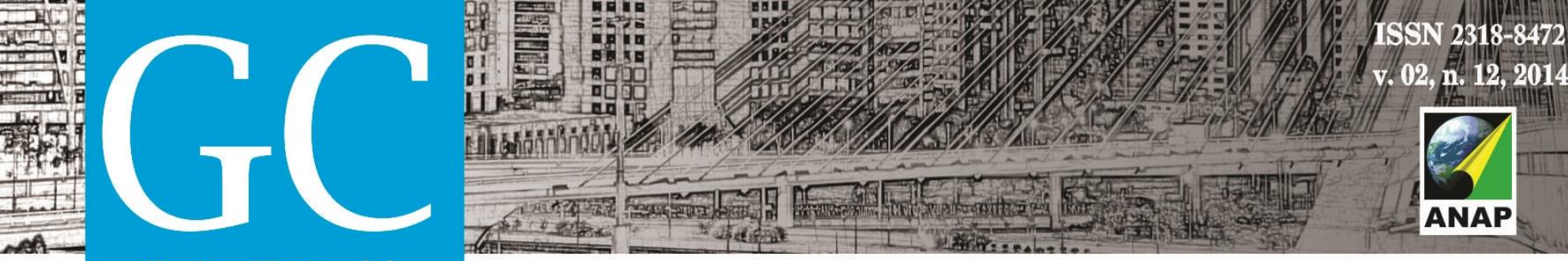

Revista Nacional de

Gerenciamento de Cidades

Assim, o ganho inicial de viagens mais rápidas e confortáveis é rapidamente anulado com a introdução gradativa de passageiros em sistemas saturados desde seu projeto, o qual já previa um número de passageiros incompatível com a capacidade dos meios, gerando maiores custos de readaptação forçada e artificial destes sistemas. Tsokalis (2009) menciona que na etapa de planejamento de uma via deve-se considerar o entorno e seu uso futuro para que, ao final da construção de toda a estrutura, possa-se obter a maximização do investimento e adiar a necessidade de expansões no futuro. $O$ mesmo autor admite que a construção de uma via não deve ser cristalizada no tempo, mas afirma que quanto maior for o tempo de remodelamento e expansão melhor será o uso da estrutura.

\section{4- TERRA BRASILIS, TERRA AUSTRALIS: POLÍTICAS E DISPONIBILIDADE DE RECURSOS}

Independente da posição econômica global de cada país e de sua capacidade de gerar mais riquezas de forma contínua ao longo do tempo, tanto Brasil como Austrália possuem muitas similitudes na aplicação de seus recursos para a estruturação de políticas de transportes em suas principais cidades objetivando formar uma rede nacional de circulação.

Ambos os países possuem como principal modo de transportes os veículos rodoviários, sendo observado que ao longo do século $\mathrm{XX} 0$ investimento em tecnologias e novos mecanismos de operação dos meios avançaram bastante na Austrália em diversas cidades, ao passo que no Brasil este avanço ocorreu a partir dos anos 1970 com (principalmente) o advento do novo plano diretor do município de Curitiba (PR), o qual introduziu novos mecanismos e abordagens do sistemas de transporte frente ao espaço urbano. Estes dois assuntos serão abordados um pouco mais adiante nesta mesma etapa.

Com dimensões continentais em ambos os países, a opção pelo sistema rodoviário como principal modo de transporte gera custos altíssimos de operação e manutenção, devido aos elevados custos de implantação inicial por quilômetro e 


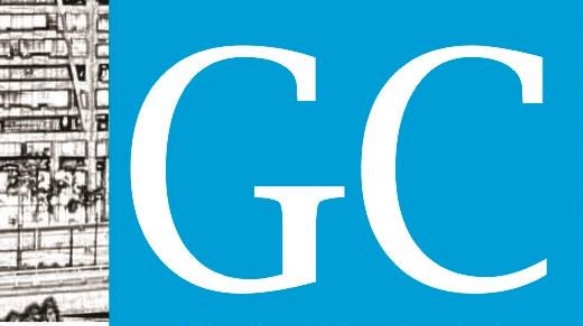

Revista Nacional de

Gerenciamento de Cidades

em conjunto com a sociedade presente em cada espaço. As políticas públicas, entre os entes federados, deveriam estar sempre alinhadas a um projeto único, para não gerar a superposição de recursos e esforços em determinados planos, conforme observado em alguns projetos metropolitanos, onde alguns municípios são beneficiados com mais recursos em detrimento da distribuição baseada em critérios equitativos e proporcionais conforme suas necessidades, causando distorções e baixa efetividade na aplicação dos projetos.

\section{REFERÊNCIAS BIBLIOGRÁFICAS}

ABS. Australia National Census 2011. Canberra (Austrália): The Australian Bureau of Statistics Publishing, 2012.

AFG. Australia General Information. Canberra (Austrália): Australia Oficial Publishing, 2014.

BADCOCK, Blair. The Urban Programme as an Instrument of Crisis Management in Australia. Londres (Reino Unido): Urban Policy and Research (Volume 11, Issue 02) (The Taylor and Francis Group), 2008.

BANISTER, David. Integrated Transport: From Policy to Practice. Londres e Nova York: Routledge, 2010.

BARAT, Josef. Logística, Transporte e Desenvolvimento Econômico. São Paulo: Editora CLA, 2007.

BRYANT, Christopher (org). The City's Countryside: Land and it's management in the RuralUrban Fringe. Londres (Reino Unido), Longman Publishing, 1982.

CHIAVENATO, Idalberto. Administração Financeira: Uma Abordagem Introdutória. Rio de Janeiro: Elsevier, 2005.

CORRÊA, Roberto Lobato. Estudos sobre a Rede Urbana. Rio de Janeiro: Bertrand Brasil, 2006.

DIT. Australian Report About National Infrastructure Conditions. Canberra (Austrália): Australia Oficial Publishing, 2013.

FERRAZ, Antônio Clóvis (org). Transporte Público Urbano. São Carlos: Rima, 2004.

FREESTONE, Robert. Cities, Citzens and Environmental Reform: History of Australian Town Planning Associations. Sydney (Austrália): The Sydney University Press, 2009.

GOUVEA, Ronaldo. A Questão Metropolitana no Brasil. Rio de Janeiro: FGV Editora, 2005.

IBGE. Censo Populacional de 2010. Brasília: Editora IBGE, 2010.

KOTLER, Philip (org.). Princípios de Marketing. Rio de Janeiro: Pearson, 2000. 
